\title{
Preserved Simple and Impaired Compound Movement After Infarction in the Territory of the Superior Cerebellar Artery
}

\author{
H.P. Goodkin, J.G. Keating, T.A. Martin and W.T. Thach
}

\begin{abstract}
A patient with an infarct in the distribution of the right superior cerebellar artery was studied with regard to his ability to make simple movements (visually triggered, self-terminated ballistic wrist movements), and compound movements (reaching to a visual target and precision pinch of a seen object). Movements on the right side of the body alone were affected. Control movements were made by the normal left upper extremity. Wrist movement on the right side was normal in reaction time, direction, peak velocity, and end-point position control as compared to the left. By contrast, both reaching and pinching movements on the right were impaired. Reaching movements showed marked decomposition of the compound elbow-shoulder movement into seriatim simple movements made alternately at elbow and shoulder. Pinching movements were not made, and instead winkling movements (a movement of index alone) were substituted. These results are compared to similar results of controlled inactivation of the cerebellar dentate nucleus in monkeys. We conclude that one function of the cerebellum may be to combine elements in the movement repertoires of downstream movement generators. When that ability is lost, a strategy may be voluntarily adopted of using the preserved simple movements in place of the impaired compound movements.
\end{abstract}

RÉSUMÉ: Préservation des mouvements simples et altération des mouvements complexes après un infarctus dans le territoire de l'artère cérébelleuse supérieure. Nous avons étudié un patient ayant un infarctus dans le territoire irrigué par l"artère cérébelleuse supérieure droite quant à sa capacité d'exécuter des mouvements simples (mouvements ballistiques du poignet à déclenchement visuel, auto-limités) et des mouvements complexes (atteindre une cible visuelle et pincer avec précision un objet situé dans le champ de vision). Seulement les mouvements du côté droit du corps étaient affectés. Des mouvements contrôles étaient effectués par le membre supérieur gauche normal. Le mouvement du poignet droit était normal comparé au gauche quant au temps de réaction, à la direction, à la vélocité maximale et au contrôle de la position au point d'arrivée. Par ailleurs, les mouvements exécutés pour atteindre ou pincer du côté droit étaient atteints. Les mouvements pour atteindre une cible manifestaient une décomposition marquée de la composante épaule-coude en des mouvements simples, successifs, faits alternativement au coude et à l'épaule. Les mouvements de pincement n'étaient pas effectués et des mouvements oscillants y étaient substitués (mouvements de l'index seulement). Ces résultats sont comparés à des résultats similaires d'inactivation contrôlée du noyau dentelé chez le singe. Nous concluons qu'il est possible qu'une des fonctions du cervelet soit de combiner des éléments du mouvement appartenant aux répertoires des générateurs de mouvements situés en aval. Quand cette capacité est perdue, une stratégie utilisant des mouvements simples qui sont préservés peut être substituée volontairement à l'utilisation des mouvements complexes normaux.

Can.J. Neurol. Sci. 1993; 20 (Suppl. 3): S93-S104

Signs of cerebellar damage prominently include asynergy and decomposition of compound movement. Asynergy is the inability to contract (and relax) many muscles simultaneously and in complementary fashion so as to achieve a smooth and accurate movement. ${ }^{1}{ }^{2}$ Decomposition of movement is the moving of each of several joints one at a time instead of in synchrony. ${ }^{3}$ Decomposition is usually assumed to be the direct result of asynergy. The mechanism underlying the two signs has historically been a subject of debate. Fluorens first asserted that the essential problem in cerebellar disorders of movement was one of incoordination of the body parts in compound move- ments. ${ }^{4}$ Holmes showed that cerebellar ablation may affect virtually all of the measurable parameters of movement-direction, force, acceleration, velocity, range, timing, and the ability to hold a position. He showed that simple movements were affected as well as compound, and stated (but did not prove) that the errors in the former summed to give the relatively greater error in the latter. As to mechanism, Holmes proposed that the role of the cerebellum was simply to tune up its down-stream targets so that their functions were performed optimally. ${ }^{3}$

Recent authors have elegantly confirmed many of Holmes' findings, especially as regards abnormalities in recordable

From the Department of Anatomy and Neurobiology, Neurology and Neurosurgery, and The Irene Walter Johnson Rehabilitation Research Institute, Washington University School of Medicine, St. Louis, Missouri

Reprint requests to: Dr. W.T. Thach, Department of Anatomy and Neurobiology, Neurology and Neurosurgery, and The Irene Walter Johnson Rehabilitation Research Institute, Box 8108, Washington University School of Medicine, 660 South Euclid Avenue, St. Louis, MO, U.S.A. 63110 
parameters of movement. Frequently mentioned are slight visuo-manual tracking delays, errors of direction, velocity, acceleration and deceleration, and of timing of muscle contraction. ${ }^{5-10}$ Presumed to be present in simple movements, these various errors are proposed to combine to cause the relatively greater errors seen in the compound movements (cf Becker et al. $\left.{ }^{6}\right)$. This position would seem to have been supported by the finding in laboratory animals of cerebellar neural discharge that leads movement onset and that correlates with the direction, position, velocity, and force of movement, as if it played a direct role in controlling these parameters of movement. ${ }^{11-17}$

Yet one may question whether there has been adequate examination of simple movements to warrant the acceptance of the original premise that they are impaired in all the above aspects. Most of the studies cited above involve movement of more than one joint of the arm or the combination of eye-tracking with wrist-tracking. In our own analysis of wrist movements after inactivation of the cerebellar nuclei in monkeys and in several cases of cerebellar damage in humans, we find that this simple movement may be nearly or entirely normal. ${ }^{18-20}$ If this is generally true across other simple movements, then the profound error that occurs in compound movements must be greater than the sum of the errors of their simple movement components.

We suggest that the "asynergy" of compound movement reflects a fundamental loss of cerebellar ability both to modulate downstream movement generators (as proposed by Holmes) and to synthesize compound movements from simpler components (as proposed by Fluorens). We further show that single joint movements are substituted where compound movements can't successfully be used, and argue that this is both a voluntary strategy and the basis of "decomposition of movement". We further argue that decomposition of movement is an effective and trainable strategy in the rehabilitation of these patients.

Some of this work has been briefly presented in abstract form. ${ }^{21}$

\section{METHODS}

\section{The patient}

Following coitus, a 60-year-old right handed man developed difficulty in standing and walking, with a tendency to fall to the right, together with headache, nausea, and vomiting. He had a previous history of insulin-dependent diabetes mellitus and hypertension, and had "given up smoking" but continued to chew cigars. On examination $(2 / 25 / 90)$, he was alert and oriented as to time and place. Visual fields were intact and the optic discs were sharp. Pupils were of equal size and reacted to light and accommodation. Extraocular movements were full, without nystagmus. Facial sensation and movement, hearing, gag reflex and swallowing, sternocleidomastoids and trapezii, and tongue movements were normal. Speech was thought to be slightly slurred. Power was normal, there was no drift of the outstretched arms. Stretch reflexes were $2+$ and symmetric; plantar responses were flexor. Somesthesis was normal. Fine finger movements were described initially as normal, but there was dysmetria on the finger-nose-finger test on the right, with truncal ataxia and a tendency to fall to the right.

A CT scan showed a cerebellar lucency interpreted as an infarct in the distribution of the right superior cerebellar artery. There was no midline shift or hydrocephalus. The electrocardiogram was normal except for 1 st degree heart block.

Over the course of two days, the patient became increasingly lethargic, and developed partial 6th and 7th nerve palsies. A CT scan showed obliteration of the 4th ventricle and dilation of the 3rd and lateral ventricles. He was given intravenous Mannitol, and taken to the operating room where a posterior craniotomy was performed. Ischemic cerebellar cortex herniated through the dural incision, and upon deeper explo- ration, necrotic and liquified cerebellar tissue issued forth under great pressure. Non-viable tissue was resected with suction and electrocautery. CSF flow was restored and the cerebellum was lax as the dura was closed. The patient quickly regained alertness. A CT scan showed no change in the area of tissue damage, and reduction of size of $3 \mathrm{rd}$ and lateral ventricles.

Physical therapy was directed at improving his gait. By the time of discharge, he walked with a simple cane and moved chiefly from the hip joint. One year later, he walked without a cane. Occupational therapy was directed at improving use of the upper extremity. He was taught to brace the elbow when using the right arm to hold and drink from a glass, and to write and perform many activities with the left hand and arm. At the time of discharge, he could reach for objects with the right upper extremity: he decomposed the movement, but had no overshoot. There was minimal action tremor. The chief disability of which he continued to complain was clumsiness of the right hand and finger movements. He could no longer manipulate coins, button clothes, or write with the right hand. Yet he returned to work supervising his surplus metal company and driving a large truck.

\section{The tasks}

1) Simple movement of the wrist to a target position - "Jump". The patient inserted his hand with fingers extended into a mitten-shaped manipulandum (Figure 1a) which was rotated in the horizontal plane about the vertical axis of the patient's wrist. The rotational position of the wrist was displayed as the horizontal position of a thin $\left(1^{\circ}\right)$ vertical line (cursor) on an oscilloscope screen. The patient was told to maintain the cursor within a thick $\left(20^{\circ}\right)$ vertical beam (target) on the screen. After a randomly varied hold interval of $1-4.5$ secs, the target suddenly moved $60^{\circ}$ in the opposite direction to a new location. The subject had to react and move to the new target location within $500 \mathrm{~ms}$. Subjects learn to do this while looking at the old and the new target locations. After the period of training, the movement was visually initiated and self-terminated, but did not require visual information for trajectory or for termination. Thus, after 20 or so trials, gaze often did not shift with the target jump. The task was performed in blocks of 20 trials in flexion directions for the right and left hand. 2) Compound movement of shoulder and elbow in pointing. The patient sat in a chair with forearms placed on the arm rests and was asked to touch with the tip of the extended index finger a target placed directly in front of him (Figure 1b). The specific instruction was to touch the target as accurately as possible, speed not being an issue. Normally, the shoulder flexed and the elbow extended simultaneously, so that the fingertip followed a relatively straight trajectory during the movement. The movement was videotaped and analyzed with a Peak Performance Video Motion Analysis system. 3) Compound movement of thumb and index finger in pinching. The patient was asked to retrieve a coin (US quarter-dollar, $\$ .25$ ) which protruded about $1 / 8$ th inch from a deep narrow well in a Perspex block (Figure 1c). Normally, a subject would retrieve the quarter with a coordinated pinch of the tips of thumb and forefinger on the edge of the coin in one trial.

\section{RESULTS}

1) Simple movements-ballistic flexion of the wrist. Figure 2 shows the results of the visually-triggered targeted ballistic wrist movement on the day the subject was first seen in the Movement Analysis Laboratory (4/11/90). Figure 2a shows 20 position traces each of flexion of the right (affected side) and the left (normal side) wrist. The amount of initial overshoot and the final end position is identical. The only difference in the two wrist movements is a slight oscillation (seen as one undershoot following the overshoot) in the right hand. Figure $2 b$ shows the reaction times and Figure $2 \mathrm{c}$ the peak velocities of the right and left wrist. The reaction times are not significantly different (Mann-Whitney test); indeed, the tendency was for the right to be slightly faster than the left (the subject was previously right handed). Neither are the peak velocities significantly different.

2) Compound movement of shoulder and elbow in pointing. Figure 3 shows the results of normal pointing with the left hand. 
Figure $3 \mathrm{a}$ shows stick figures of upper arm and forearm positions at frame intervals of $33 \mathrm{~ms}$ and the trajectory of the index finger tip (I). The angulation of shoulder and elbow is such that the stick figures move smoothly from one to the next and do not overlap. The trajectory is a relatively straight line from the rest position to the target position. Figure $3 \mathrm{~b}$ shows six successive trajectories of the wrist, which are relatively uniform. Figure 3c shows that the angles at the flexing shoulder and the extending elbow (ordinate) change continuously over time (abscissa), in a smooth curve without inflexion points. Figure $3 d$ shows a plot of the elbow angle (ordinate) against the shoulder angle (abscissa). The movement begins at the lower right of each curve. Note that to make a relatively straight trajectory of the wrist, the elbow extends and the shoulder flexes, but the elbow angle/shoulder angle is not linear. The relationship is an upward sloping, smooth curve, with a changing ratio of extending elbow angle/flexing shoulder angle as the movement progresses.

Figure 4 shows the results of pointing with the abnormal right arm on the first examination in the Movement Analysis Laboratory (4/1 1/90). In Figure 4a, the stick figures merge for a number of frames in a number of positions, indicating lack of continuous joint angulation over time. Moreover, the upper arm lines merge when the forearm lines do not, and the forearm lines merge when the upper arm lines do not, which is caused by the shoulder fixating while the elbow bends and vice versa. The trajectory of the tip of the index finger (I) is irregular rather than straight. In Figure $4 \mathrm{~b}$, the six successive wrist trajectories show variability within and across trials, and of several sorts. First, there is a slight tremor at slightly less than $3 \mathrm{~Hz}$. Second, there are changes in direction that are at odd and varying intervals. In Figure $4 c$, decomposition of this compound movement into seri- atim simple movements is illustrated. In frames $1-3$, the elbow flexes before the shoulder begins to move; in frames $4-16$, the shoulder flexes while the elbow fixates; in frames $17-40$, the elbow extends and the shoulder flexes simultaneously. Thus, decomposition is revealed by an initial elbow flexion before the shoulder begins to move, then alternate movement at one joint and fixation of the other. The movement was inaccurate, with a tendency to overshoot (not shown). In Figure 4d, the plots of shoulder angle/elbow angle also document decomposition of movement. Decomposition is revealed by vertical or flat segments in the curves. As the movement begins in the lower right end of each curve, an initial downward-directed vertical segment indicates the elbow flexing. The initial elbow flexion is seen as short vertical segments in two trials without corresponding change at the shoulder and a downward slope in 3 others with accompanying shoulder flexion. Then the curves change direction and are flat while the shoulder flexes without change occurring at the elbow. Finally, the curves slope upward as the elbow extends and the shoulder flexes. Note that the initial elbow flexion is not present on the normal side in Figures $3 \mathrm{c}$ and $3 \mathrm{~d}$. Note also the considerable variability from trial to trial, with abrupt changes in the direction of the curve occurring at different values of elbow and shoulder angle for each curve.

Figure 5 (one week later - 4/18/90) shows further change in the pointing movement. In Figure 5a, the stick figures again show overlap of the upper arm or the lower arm (but not both) in successive frames. This again indicates lack of coordinated angulation of movements of the two joints. The fingertip trajectory is both irregular and curved. In Figure 5b, the six successive wrist trajectories show little or no tremor, but instead a curvilinear course with abrupt changes in direction. In Figure

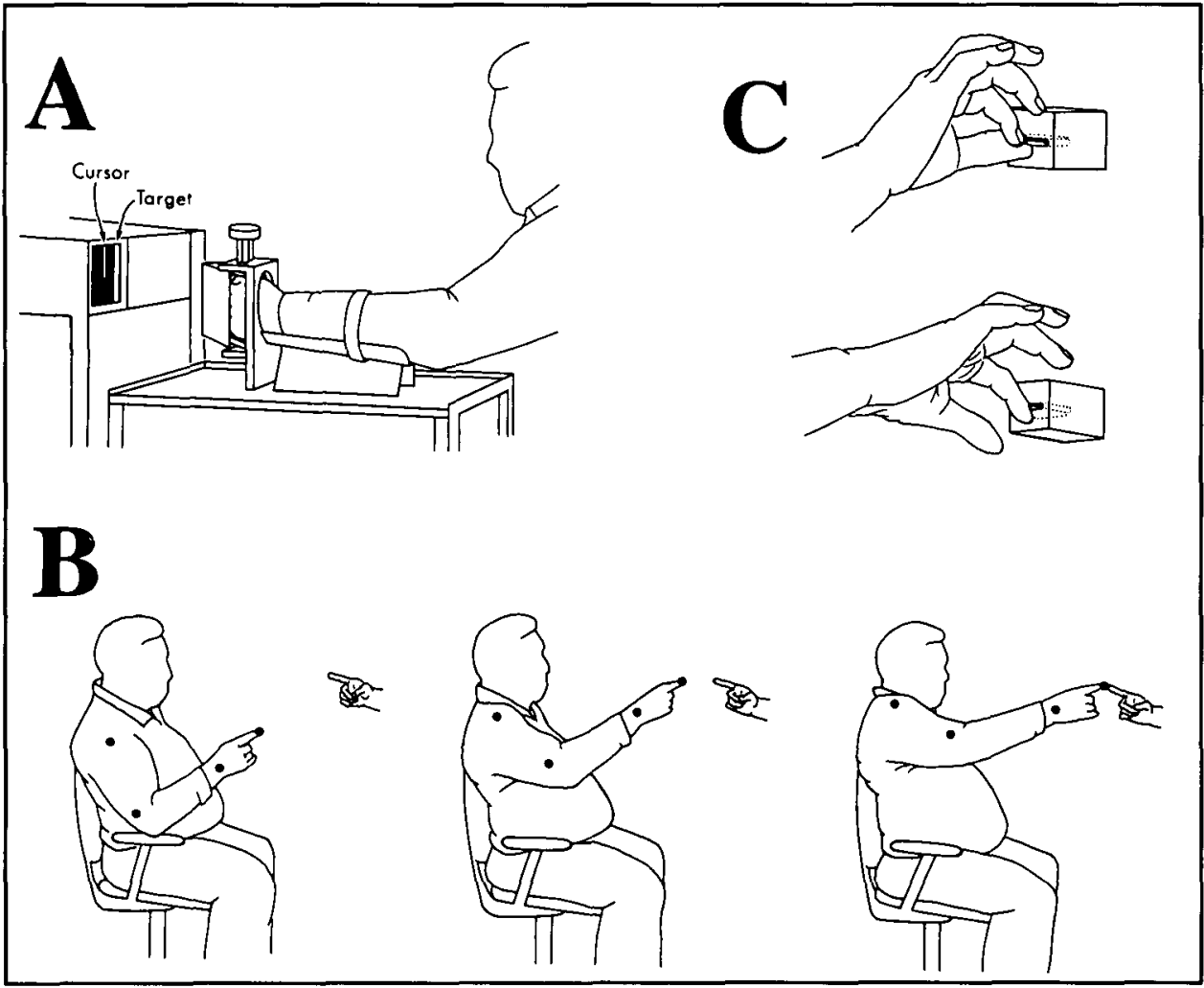

Figure l-The tasks. A: Simple ballistic wrist movements to a visual target "Jump" (see Methods). B: Compound movement of shoulder and elbow in normal pointing. C: Movement of thumb and index finger in correct twodigit pinching (top) and incorrect single-digit "winkling" (bottom) pinching. 


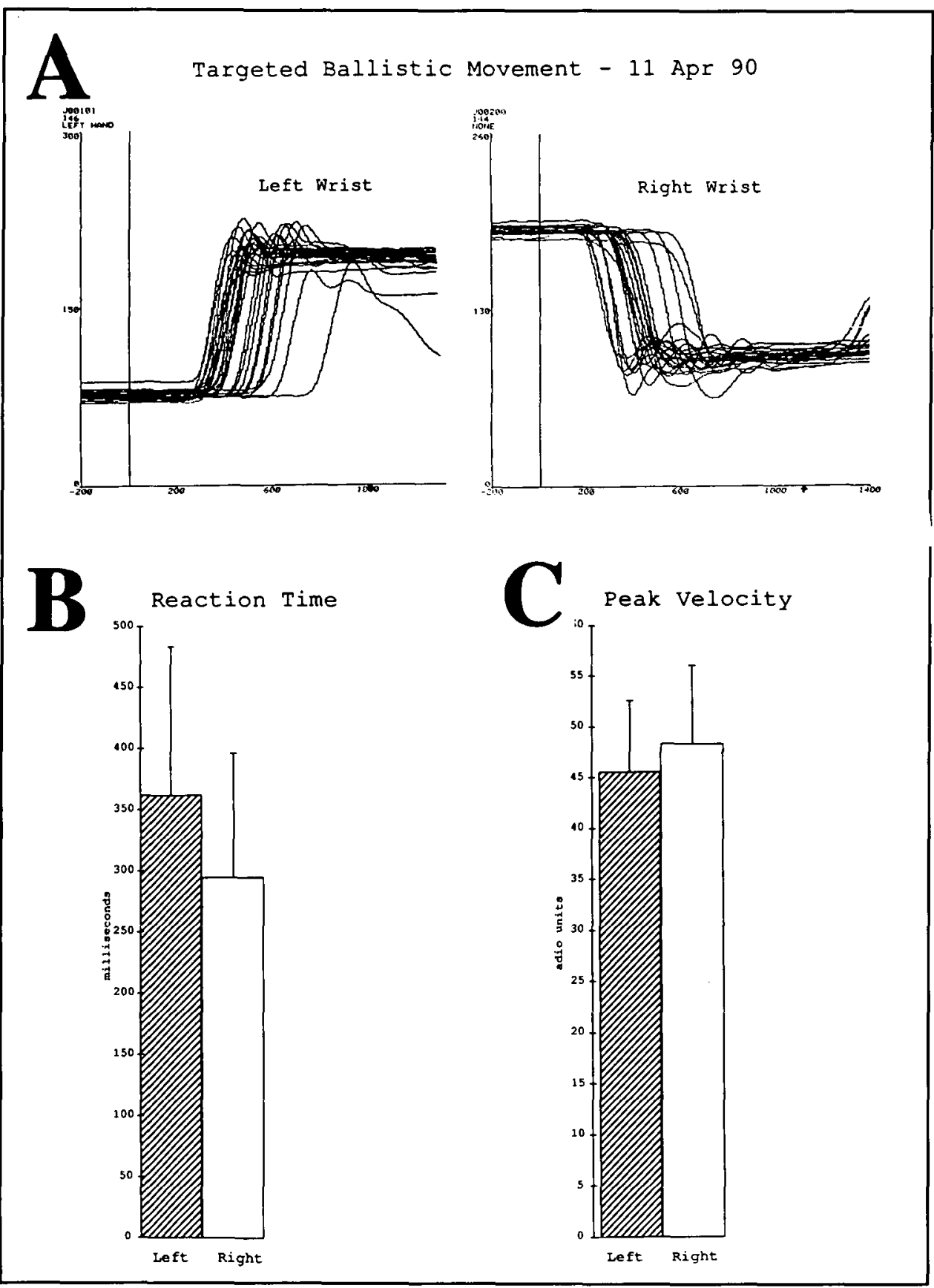

Figure 2 - Simple ballistic wrist flexion movements to a target - "Jump". A: Individual trials, superimposed. Vertical line to the right of the ordinate represents onset of target movement (stimulus for the subject to move). Left, normal side; right, affected side. B: reaction times of right and left wrist movements. $C$ : peak velocities of right and left wrist movements. Except for a slight tendency to oscillate, the right affected hand show's no impairment on this task.

$5 \mathrm{c}$, the measures of joint angle over time show that the decomposition of movement persists and may have increased. In frames $1-4$, the elbow again flexes while the shoulder is fixed; in frames $5-10$, the shoulder flexes while the elbow is fixed; in frames $11-20$, shoulder and elbow flex together, as in the earlier session. However, from frame 20 to the end, the shoulder is fixed while the elbow extends to complete the movement. In Figure 5d, the plot of shoulder angle against elbow angle shows both vertical and flat segments. Two trials show the initial vertical components of elbow flexion without shoulder change. Subsequently, two trials show flat components of shoulder flexion without elbow change. However, there is much less acrosstrial variation. The curves more nearly overlap. There is an inflexion point across all curves at nearly the same point in the elbow extension/shoulder flexion relationship: before the break the shoulder changes more than the elbow (flattish); after the break the elbow changes more than the shoulder (more vertical-compare to Figure $3 \mathrm{~d}$ ). This shows that the process of decomposition of movement has become more stereotyped.

3) Compound movements of thumb and forefinger in pinching. Figure $1 \mathrm{c}$, top, shows the normal pinch with the thumb and index on the edge of the quarter. Figure lc, bottom, shows a different strategy in which the tip of the index finger contacts the quarter and flexes to pull it out of the slot (winkling). This occurred despite the instruction to "use your thumb and forefinger to pinch the coin". Figure 6a graphs the results of correct pinch and incorrect winkling (a single digit strategy) with the left and right hands on the first session in the Movement Analysis Laboratory (4/11/90). The left (normal) hand consistently used the pinch; the right (affected) hand the single digit 
strategy. Figure $6 \mathrm{~b}$ shows the results of an examination four months later (8/30/90). There is still the strong tendency for the left hand to pinch and the right hand to employ single digit strategies. Only one pinch was seen with the right hand. As if the compensatory strategy had been carried over by mistake to the normal hand, one winkle was seen with the left hand. Figures $6 \mathrm{c}$, d, e graph the results of this second later session. Figure $6 \mathrm{c}$ shows the time (number of frames: interframe interval $=33 \mathrm{~ms})$ taken for the normal left hand $(2.9 \mathrm{~s})$ and the clumsy right hand $(8.3 \mathrm{~s})$. Figure $6 \mathrm{~d}$ shows the average number of attempts per trial -2.5 with the left and 5.5 with the right. Figure $6 e$ shows the average number of fingers used for each successful trial -1.9 with the left, and 1.1 with the right. These measures document the strong tendency to resort to single digit strategies with the affected right hand.

\section{Discussion}

The sparing of wrist movements and the impairment of reaching and pinch is not likely to be an artifact due to the lesion "missing" the wrist representation area. Previous studies in macaques have supported a somatotopic scheme within each of fastigial, interposed, and dentate nuclei, with lower extremity anterior, head posterior, distal parts medial, and proximal parts lateral. The upper extremity is represented in the mid-portion. ${ }^{18-}$ 20,22-24 Reaching deficits resulted from inactivation of the lateral (proximal body) part of the nucleus more than the medial; pinching deficits of the medial (distal extremity) more than the lateral. ${ }^{19}$ Neither the reaching or the pinching deficit was seen after inactivation of interpositus or fastigius. ${ }^{19,20}$ In the patient discussed here, the fingers were impaired in pinch, and the elbow and shoulder in pointing. It is therefore unlikely that the lesion could have skipped the wrist representation area in between.

In our patient, the infarct was seen by CT to be in the territory of the superior cerebellar artery (Figure 7a, b). Cortical tissue was damaged in the right vermal zone (which projects to the right fastigius), correlating with his tendency to fall to the right, and in the intermediate zone (which projects to the globose and emboliform nuclei), correlating with his action tremor. The cortical damage also included a medial portion of the lateral zone (which projects to the medial portion of the dentate), correlating with the persistently impaired pinch. But since Amarenco and Hauw found that the dentate is always supplied exclusively by the superior cerebellar artery, it is likely that the dentate was directly involved in the infarct, accounting for the reach and pinch deficits. ${ }^{25,26}$

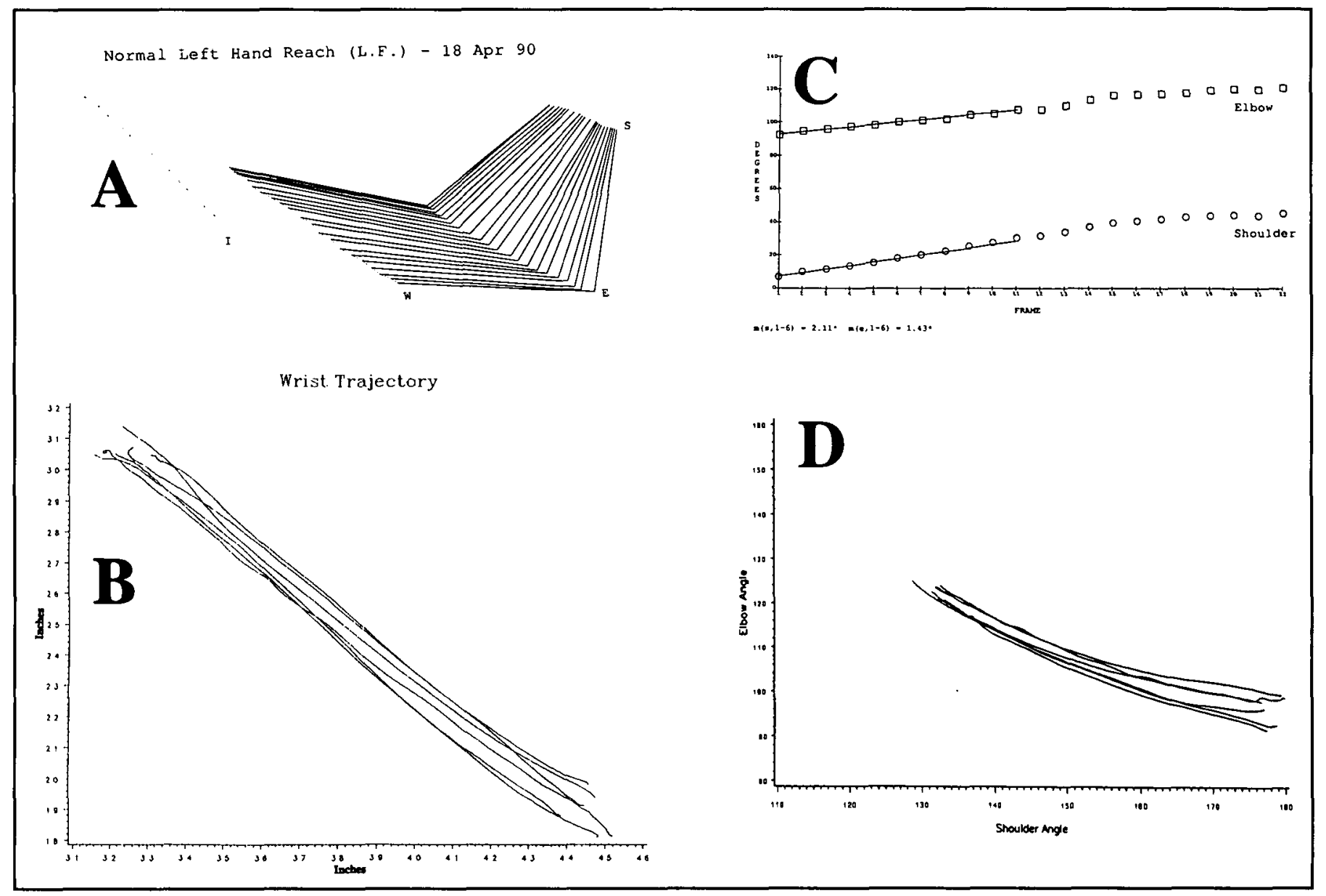

Figure 3 - Shoulder and elbow movements in normal pointing. A: stick figures of upper left (normal) upper arm and forearm positions at frame intervals of $33 \mathrm{~ms}$ and the trajectory of the index fingertip (I). B: six sequential wrist trajectories. $C$ : angles at the shoulder and the elbow (ordinate) plotted against time (by frame number, abscissa). D: elbow angle (ordinate) plotted against shoulder angle (abscissa). 
Simple movements are minimally affected by cerebellar lesion. In instrumented ballistic movements of the wrist to a target position, the affected right hand was almost identical to the normal left hand. Onset time (measured as visuo-manual reaction time), maximum velocity, and target endpoint was similarly attained with both hands. The subject never moved in the wrong direction.

In macaques, simple movements have been shown to be affected by cerebellar lesion. Action tremor has been produced by inactivation of interposed and dentate nuclei during instrumented elbow and wrist movement. ${ }^{18,20,27-29}$ Nevertheless, some question remains as to whether there is any significant abnormality other than tremor of simple movements. The scant 20 $150 \mathrm{~ms}$ reaction time delay and the otherwise near normalcy after cerebellar nuclear inactivation of instrumented visuallytriggered simple ballistic movements have been carefully documented. ${ }^{18.20 .30-33}$ Yet, upon dentate cooling during movements at the elbow, Flament and Hore reported not only action tremor but in addition, hypermetria. ${ }^{7}$ Their inclusion of hypermetria may be a matter of definition. Flament and Hore defined the endpoint of movement as the position at which velocity first reaches zero. Upon cerebellar nuclear cooling, their records do show overshoot, but this was always (in those records shown) part of an oscillatory process. They did not show overshoot without tremor. A clinical study of cerebellar patients gave similar results. ${ }^{34}$ Our definition of hypermetria is that of a positional overshoot without tremor, which may persist until a second attempt at movement occurs as a second reaction-time process. After muscimol and kainate inactivation of lateral dentate, we have seen this occur in reaching but not in simple wrist movements. ${ }^{18-20}$ Thus, Flament and Hore's records (e.g., Figures 2, 4) show what we would call a terminal tremor overshooting and oscillating about the endpoint, without hypermetria per se although the tremor of Figure $2 \mathrm{~d}$ is at a lower frequency than that of Figure $2 b$.

As for neural discharge correlating with parameters of simple movement, cerebellar unit firing has often been correlated with what were thought to have been single joint movements. ${ }^{11-}$ 15,17,32.35-40 Nevertheless, when animals were overtrained under loading conditions such that the agonists alone moved the wrist joint, there was no unit discharge correlation with any of the above parameters of movement (save tremor). ${ }^{29.41}$ These observations argue that the cerebellum exerts relatively little control over simple movements.

In humans, previous claims of abnormal simple movements after cerebellar damage are open to interpretation. Thus, Brown
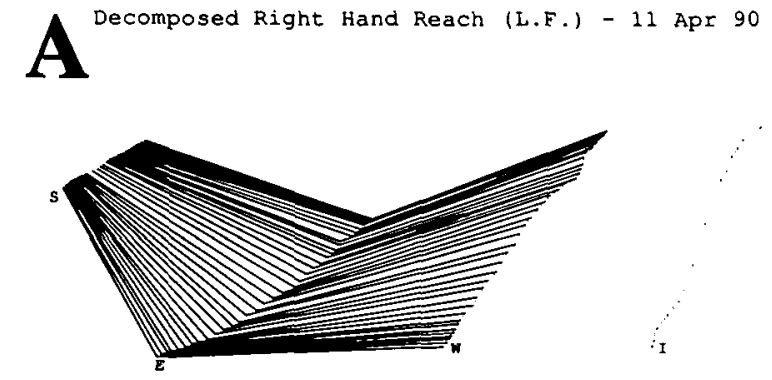

Wrist Trajectory

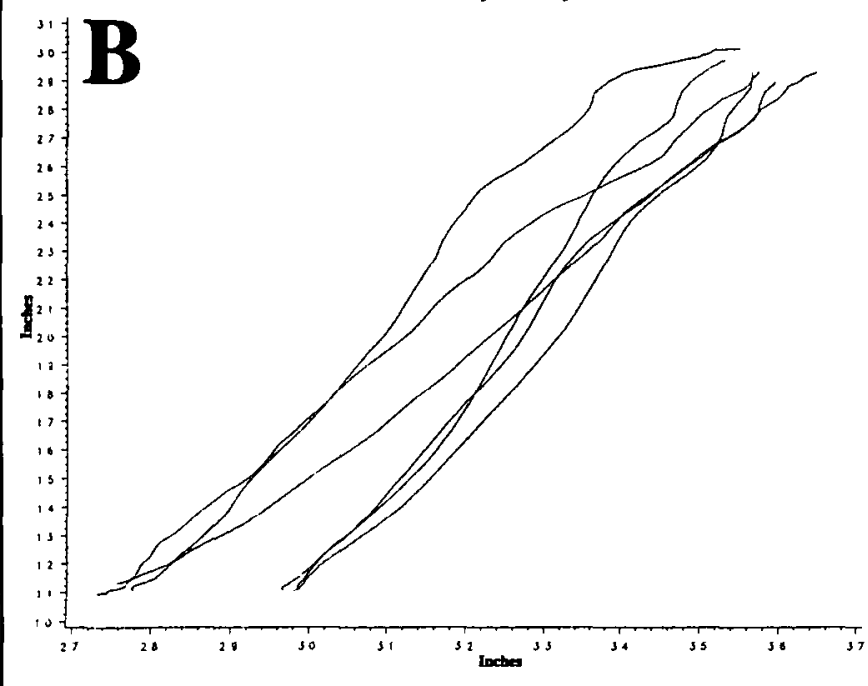

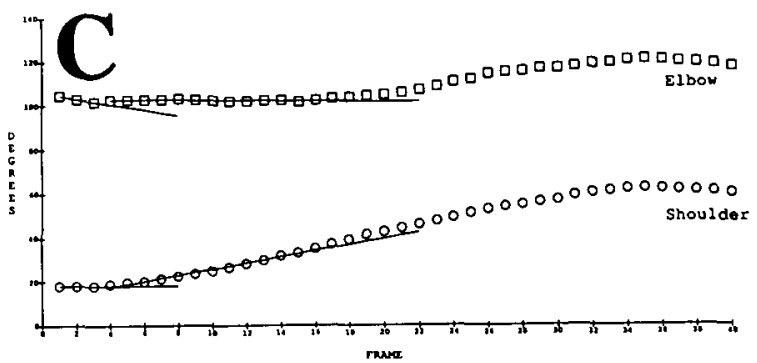

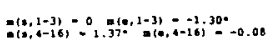

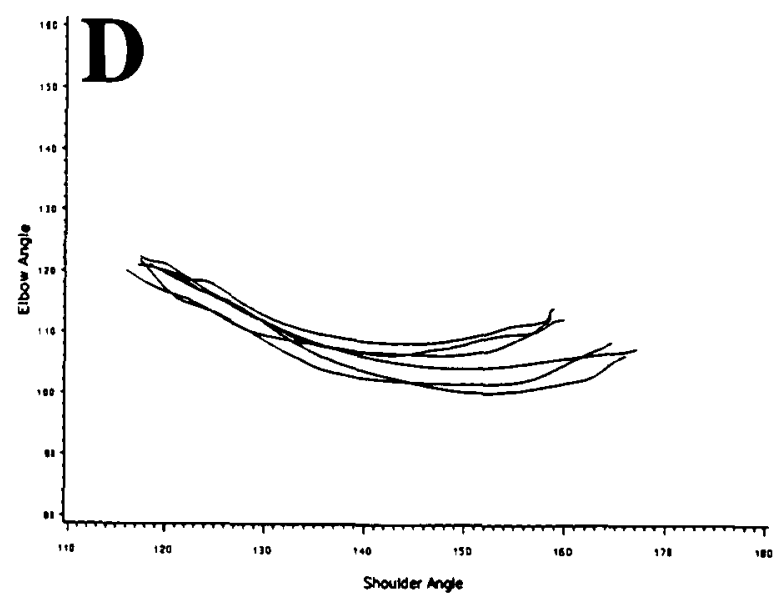

Figure 4-Shoulder and elbow movements in abnormal pointing. Displays and conventions are the same as for Figure 2. A: stick figures of right (abnormal) upper arm and forearm positions at frame intervals of $33 \mathrm{~ms}$ and the trajectory of the index fingertip (I). B: six sequential wrist trajectories. C: angles at the shoulder and the elbow (ordinate) plotted against time (by frame number, abscissa). D: elbow angle (ordinate) plotted against shoulder angle (abscissa). Trajectories are irregular and curved, and the joints tend to move one at a time (decomposition of movement). 
et al. show abnormalities of the patterns of acceleration and deceleration at the elbow, as did Flament and Hore in the monkey. ${ }^{7.8}$ However, the patterns are opposite: in humans Brown et al. show shortened acceleration and lengthened deceleration, whereas in monkeys Flament and Hore show just the reverse. It seems unlikely that these differences are due to a species difference and rather more likely that they are strategic alterations in task performance, as Brown et al. suggest for their own data. Because they are opposite, it is difficult to believe that either is fundamental. Miller and Freund reported abnormalities in finger tracking that were extreme when finger generated force to match a moving visual display (presumably tracked also by eye), and which virtually disappeared when (without vision) the finger had to generate force to nullify displacement. ${ }^{42}$ Clearly in the one case the eyes and the finger were moving together and in the other the finger alone. Sanes et al. have shown action tremor in cerebellar patients that was present when the limb was tracking a visual target (eye presumably tracking also) and absent when exerting force to resist displacement (without vision). ${ }^{43}$ Both Miller and Freund and Sanes et al. attributed the problem to a specific abnormality of the cerebellar processing of vision rather than to differences between simple and compound movements. Yet, Vercher and Gauthier have shown that in the visually guided single-joint movement, the eye and the wrist are moved coordinately. ${ }^{44.45}$ In baboons, they showed that dentate inactivation impairs the eye-hand coordination, while simple movements (eye or hand) are only slightly delayed. ${ }^{46}$

\section{Compound Movements are Preferentially Controlled by the Cerebellum and Affected by Cerebellar Lesion}

Studies of normal pointing in humans confirm the tendency to produce a nearly straight-line trajectory of the moving fingertip. ${ }^{48-51}$ To accomplish a straight line trajectory, Hollerbach and Atkeson have shown that the shoulder angle/elbow angle relationship is curvilinear and varies with the target location. ${ }^{52}$ Correspondingly, a linear relation of shoulder and elbow angle produces a curvilinear fingertip trajectory. ${ }^{52}$

In monkeys trained to reach over a horizontal surface to a target to the front, total decerebellation produced a curved (convexity outside) rather than straight trajectory. Also, there was overshoot (never undershoot) of the target. ${ }^{53}$ Recent studies have reproduced these effects by acute reversible inactivation confined to the dentate. ${ }^{19,20}$ Overshoots in excess of $6 \mathrm{~cm}$ were produced by angle errors at elbow and shoulder in excess of $30^{\circ}$.

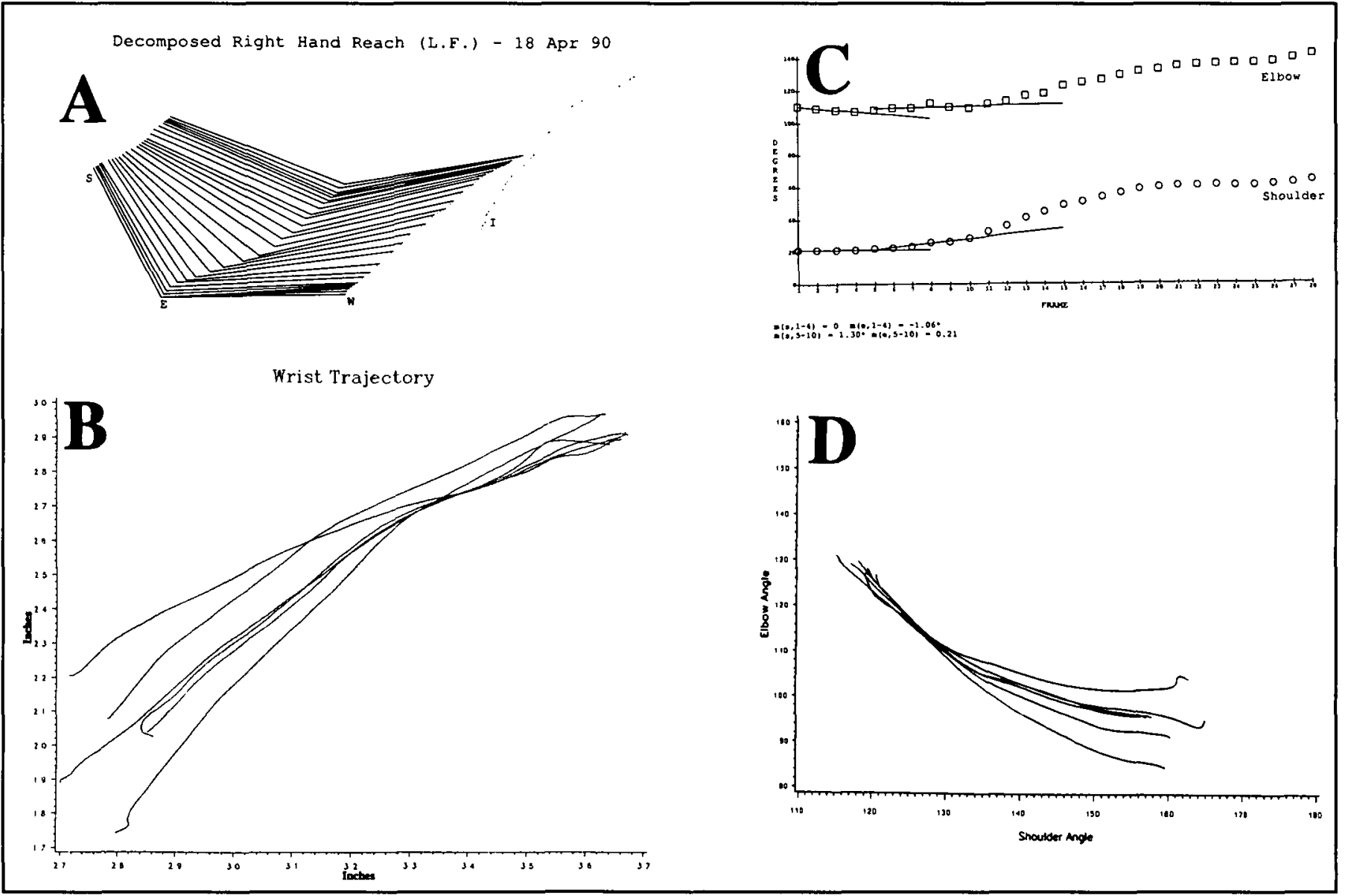

Figure 5-Shoulder and elbow movements in abnormal pointing, one week later. Displays and conventions are the same as for Figure 2. A: stick figures of right (abnormal) upper arm and forearm positions at frame intervals of $33 \mathrm{~ms}$ and the trajectory of the index fingertip (I). B: six sequential wrist trajectories. C: angles at the shoulder and the elbow (ordinate) plotted against time (by frame number, abscissa). D: elbow angle (ordinate) plotted against shoulder angle (abscissa). Trajectories are still curved, but, along with the tendency to move one joint at a time, have become more stereotyped. 


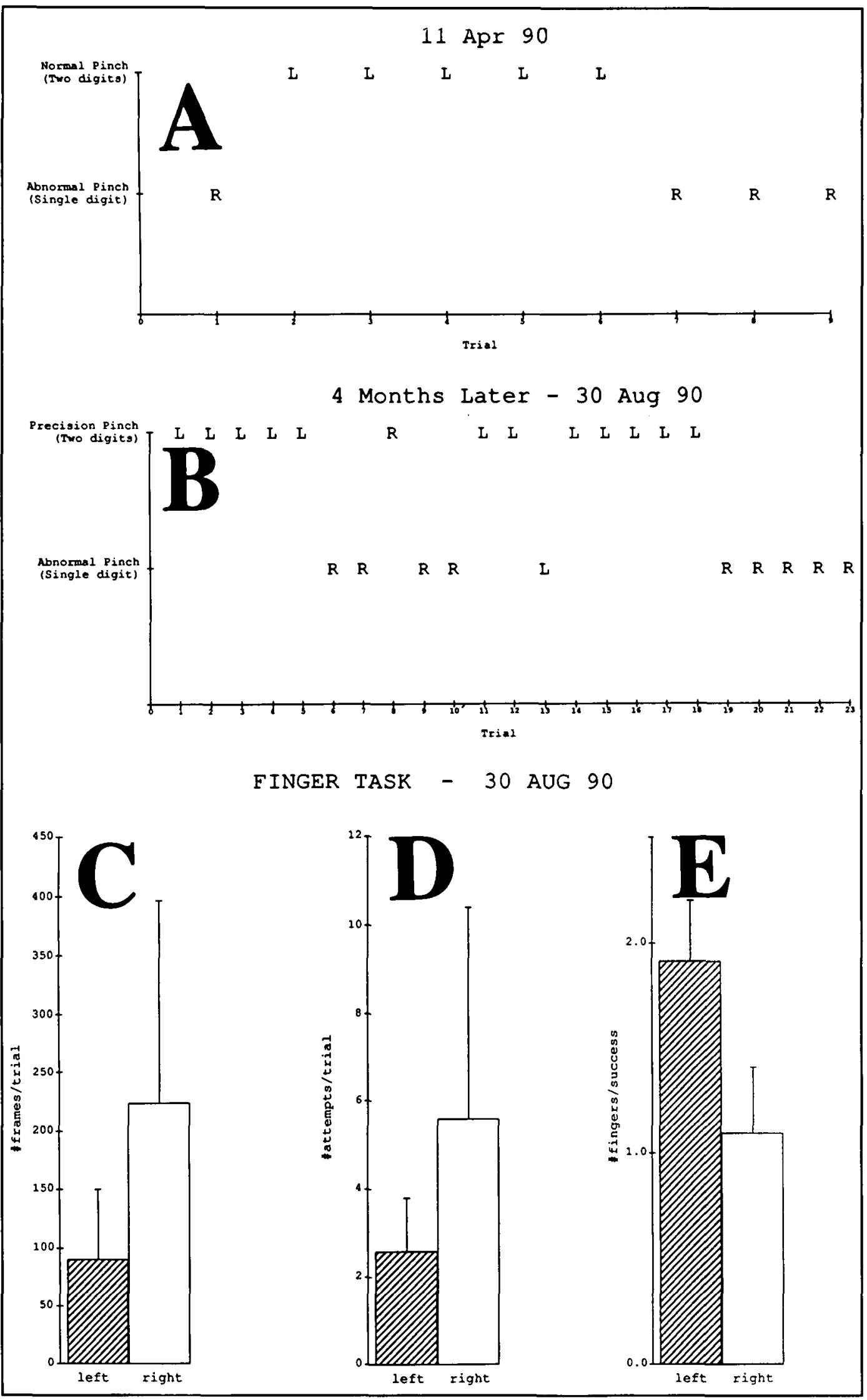

Figure 6-Movement of thumb and index finger in normal and abnormal pinching. Graphs of frequency of occurrence of correct pinch and incorrect winkling with the right and left hands. $A$ : first session. B: second session, four months later. Further results of this second later session: $C$ : time taken per trial for the normal left and the clumsy right hand. D: average number of attempts per trial with the left and right hands. $\boldsymbol{E}$ : average number of fingers used for each successful trial with the left, and right hands. Despite instruction, the subject continues to use single-digit winkling instead of two-digit pinching in the (impaired) right hand. 


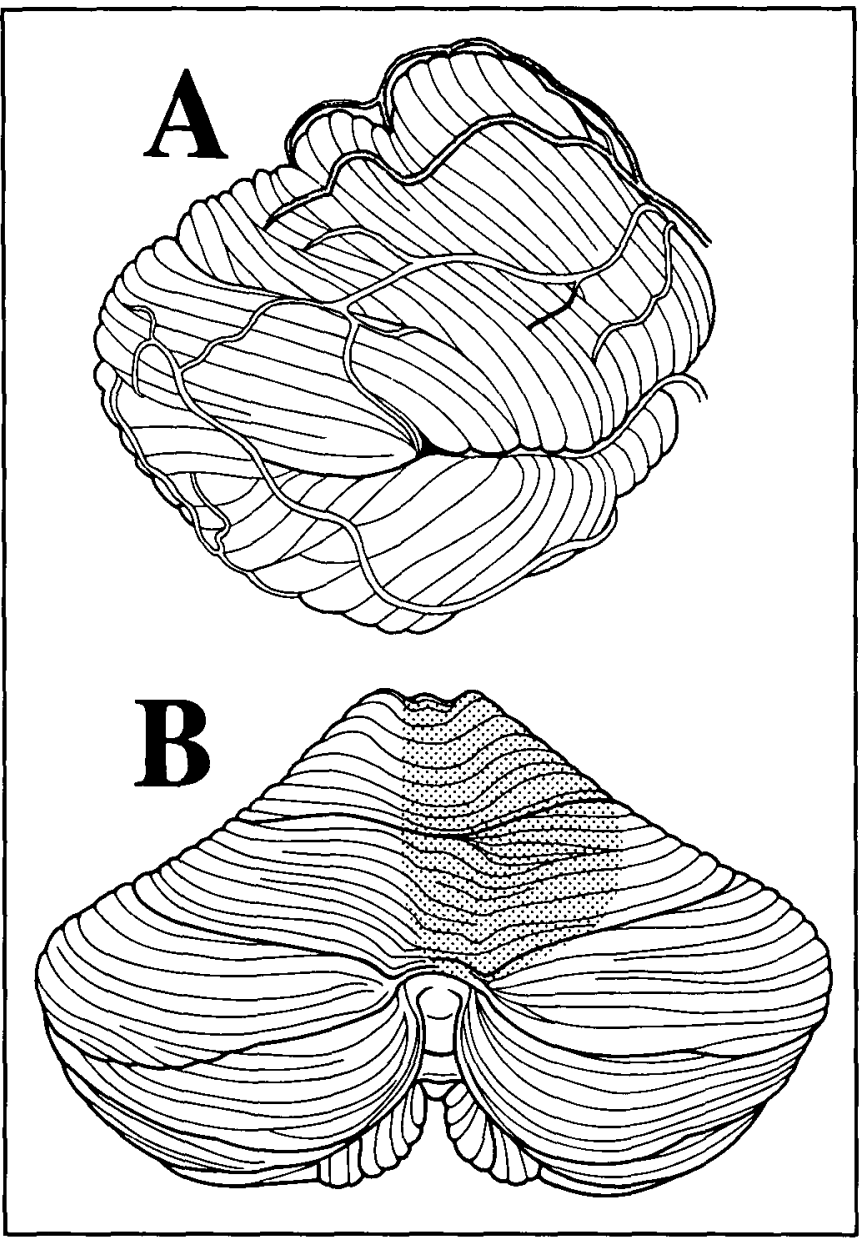

Figure 7 -Drawing of human cerebellum. A. Viewed from the right side, showing the superior cerebellar artery (shaded), and the antevior inferior and posterior inferior cerebellar arteries below it. $\boldsymbol{B}$. Viewed from above, showing the infarcted area in the distribution of the superior cerebellar artery. (Adapted from Nieuwenhuys et al., 1988 , reference 47.$)$

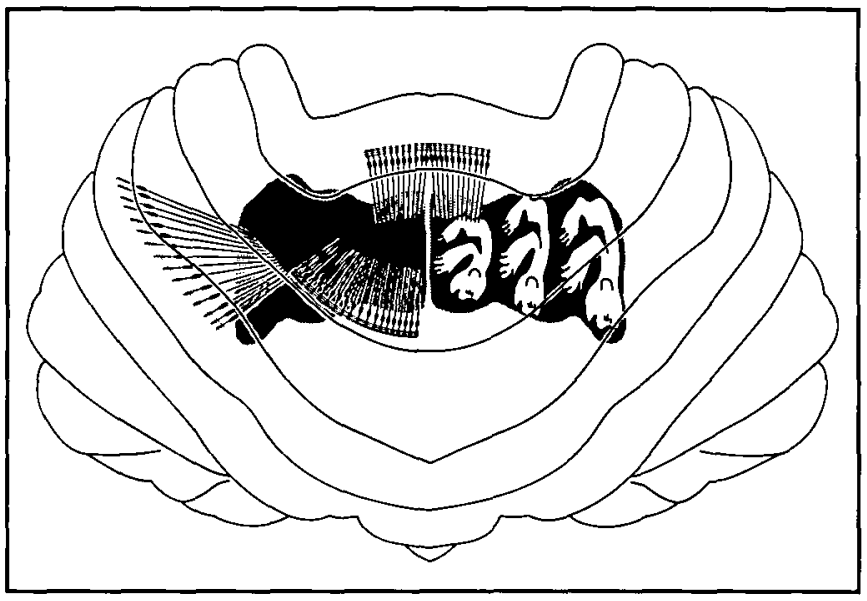

Figure 8-Diagram showing linkage into beams of Purkinje cells by parallel fibers. Beams project down onto the somatotopically organized nuclei. Purkinje cell beams thus link body parts together within each nucleus, and link adjacent nuclei together. Such linkage could be the mechanism of the cerebellar role in movement coordination (from Thach et al., 1992).
The overshoot was without tremor. In these hypermetric movements, shoulder and elbow always moved simultaneously and in synergy. No decomposition of movement was observed. On no occasion was there undershoot.

Transient inactivation of the dentate also caused clumsiness of the fingers, with difficulty or inability in using index and thumb in a precision pinch to retrieve food bits from deep narrow wells. The animals resorted to single digit strategies of raking the food bit up the side of the well (winkling) or impaling the food bit on the finger nail. Normally, digits 3, 4, and 5 either flexed and tucked out of the way or extended in a "tea cup posture". After dentate inactivation, these fingers often got caught on the edges of the food well and moved independently as the index moved to get the food bit ("spider hand").

In these same studies on dentate inactivation, visually-trig. gered ballistic wrist movements to a visual target (Jumps) were, except for reaction time delays of $20-150 \mathrm{~ms}$, normal. Endpoint tremor appeared only when interpositus was involved. In these simple movements, there was no observed consistent error in endpoint control. Abnormalities of gait were slight: dentate inactivation caused the hand and foot to rise higher off the floor than normally. Interpositus inactivation caused the hand and foot to fail to clear the floor and to drag the knuckles. Only fastigial inactivation caused the profound inability to sit, stand or walk, with falls to the side of the lesion. ${ }^{18.20 .54,55}$

In prior studies, cerebellar ablation has been shown to greatly impair compound movements. ${ }^{53-59}$ Rispal-Padel and colleagues have electrically stimulated the dentate in regions that produce compound movements only. ${ }^{60.61}$ Several reports now document that cerebellar neurons may fire in good correlation with compound movements. ${ }^{16,62}$ While none have yet compared simple and compound movements for the same cells and animals, the experiment of Schieber and Thach raises the question of whether the previous cerebellar neuron discharge correlations with the parameters of simple movements might have correlated better with occult compound movements. ${ }^{29}$

\section{Mechanism of Decomposition of Movement}

The cerebellum projects to downstream movement pattern generators that include motor cortex, red, vestibular and reticular nuclei, and spinal cord. ${ }^{22,23,63-65}$ Each of these structures is capable of generating its own pattern of movement. Motor cortex and red nucleus neurons fire in correlation with movement of single or small groups of muscles such as are used in making movements of a single joint or digit. ${ }^{66-72}$ Ablation impairs these movements preferentially. ${ }^{73-75}$ The cerebral cortex and the corticospinal pathway therefore appear to be exclusively responsible for voluntary individuated digit movements.

In light of the above data and interpretations regarding simple movements, we suggest that at least for some compound movements like pinch, cerebellar action may be required to combine the elements resident within the downstream generator. This would seem to be the simplest explanation of an exquisitely preserved ability to make wrist and single digit movements, but not pinch. The cerebellum seems to be needed to combine them. We have reviewed this question and discussed elsewhere the mechanism by which such simpler synergies may theoretically be linked together. ${ }^{20}$ This would be through the actions of the parallel fibers, which link Purkinje cells into very long beams (Figure 8) ${ }^{76}$ The parallel fiber-Purkinje cell beams 
project down upon and span the entire width of 1 or even 2 nuclei. Each nucleus has its own somatotopically arranged groupings of muscle actions or synergies which are in turn representative of the organization of the generators to which each projects. ${ }^{20}$ The combining action of the cerebellum on the elements of the downstream generator repertoires would be in keeping with the observations and theories of Fluorens, Babinski, and Rondot. 1,2,4,77

Such a combining action across joints would not explain the preservation after cerebellar lesion of compound, coordinated (albeit inaccurate) elbow and shoulder movement in reach. Reach is known to survive both cerebellar and corticospinal damage. Other evidence suggests reach may be controlled by structures in the brain stem and upper cervical cord. ${ }^{78}$ The role of the cerebellum could well be to modulate the gain or sensitivity of these downstream circuits in the way that Holmes and McKay and Murphy have proposed. 3,79

Subjects with cerebellar lesions who cannot make compound movements accurately can-and do-use instead the preserved simple movements. This is seen both in man and in monkey in the "winkling" single digit movements that are substituted for the impaired pinch. We know that these movements may be initiated and controlled without help from the cerebellum; we think it likely that they are generated by motor cortex.

This mechanism may also explain the decomposition of reaching and pointing. Decomposition was not seen after the sudden inactivation of dentate in monkeys; it must then develop over time. One can easily speculate that a brainstem reaching and pointing generator, permanently deprived of its cerebellar adjustor, can operate but never again be accurate. Therefore, when accuracy is required, the subject abandons use of the impaired brainstem generator and uses instead the intact motor cortex. The speculation would further be that, even without cerebellar input, the motor cortex can generate simple movements of near normal reaction time, speed and accuracy. The subject thus learns to move one joint at a time, seriatim, to achieve the accuracy required. There is, nevertheless a trade-off: movements are not as fast as when the brainstem reaching and pointing generator is used. This can be illustrated in a cerebellar patient by asking that reaching or pointing be performed under each of two separate instructions. Movements made "as fast as possible" are found to be coordinated at shoulder and elbow, but overshoot the mark. Movements made "as accurately as possible" are decomposed into seriatim movements at shoulder and elbow, but hit the mark accurately. This phenomenon has been observed also by others, and has been documented in this symposium (Hallett, Diener).

\section{ACKNOWLEDGEMENTS}

This work was supported by NIH grant NS 12777.

\section{REFERENCES}

1. Babinski J. De l'asynergie cerebelleuse. Rev Neurol 1899; 7: 806-816.

2. Babinski J. Asynergie et inertie cerebelleuses. Rev Neurol 1906; 14: 685-686.

3. Holmes $\mathrm{G}$. The cerebellum of man. The Hughlings Jackson memorial lecture. Brain 1939; 62: 1-30.

4. Fluorens, P. Recherches experimentales sur les proprietes et les fonctions du systeme nerveux, dans les animaux vertebres. Paris: Cervot, 1824
5. Beppu H, Suda M, Tanaka R. Analysis of cerebellar motor disorders by visually-guided elbow tracking movements. Brain 1984; 107: 787-809.

6. Becker WJ, Morrice BL, Clark AW, Lee RG. Multi-joint reaching movements and eye-hand tracking in cerebellar incoordination: investigation of a patient with complete loss of Purkinje cells. Can J Neurol Sci 1991; 18: 476-487.

7. Flament D, Hore J. Movement and electromyographic disorders associated with cerebellar dysmetria. J Neurophysiol 1986; 55: 1221-1233.

8. Brown SH, Hefter H, Mertens M, Freund H-J. Disturbances in human arm movement trajectory due to mild cerebellar dysfunction. J Neurol Neurosurg Psychiatry 1990; 53: 306-313.

9. Hallett MB, Shahani BT, Young RR. EMG analysis of patients with cerebellar deficits. J Neurol Neurosurg Psychiatry 1975; 38: 1154-1162.

10. Becker WJ, Kunesch E, Freund, H-J. Coordination of a multijoint movement in normal humans and in patients with cerebellar dysfunction. Can J Neurol Sci 1990; 17: 264-274.

11. Thach WT. Discharge of cerebellar neurons related to two maintained postures and two prompt movements. 1. Nuclear cell output. J Neurophysiol 1970; 33: 527-536.

12. Thach WT. Discharge of cerebellar neurons related to two maintained postures and two prompt movements. II. Purkinje cell output and input. J Neurophysiol 1970; 33: 537-547.

13. Thach WT. Timing of activity in the cerebellar dentate nucleus and cerebral motor cortex during prompt volitional movement. Brain Res 1975; 169: 168-172.

14. Thach WT. Correlation of neural discharge with pattern and force of muscular activity, joint position, and direction of intended next movement in motor cortex and cerebellum. J Neurophysiol 1978; 4l: 654-676.

15. Lamarre Y, Spidalieri G, Chapman CE. A comparison of neuronal discharge recorded in the sensori-motor cortex, parietal cortex, and dentate nucleus of the monkey during arm movements triggered by light, sound or somesthetic stimuli. Exp Brain Res Suppl 1983; 7: 140-156.

16. Fortier PA, Kalaska JF, Smith AM. Cerebellar neuronal activity related to whole-arm reaching movements in the monkey. J Neurophysiol 1989; 62: 198-211.

17. Soechting JF, Burton JE, Onoda N. Relationships between sensory input, motor output and unit activity in interpositus and red nuclei during intentional movement. Brain Res 1978; 152: 6579.

18. Kane SA, Mink JW, Thach WT. Fastigial, interposed, and dentate cerebellar nuclei: somatotopic organization and the movements differentially controlled by each. Soc Neurosci Abstr 1988; 14: 954.

19. Kane SA, Goodkin HP, Keating JG, Thach WT. Incoordination in attempted reaching and pinching after inactivation of cerebellar dentate nucleus. Soc Neurosci Abstr 1989; 15: 52.

20. Thach WT, Goodkin HP, Keating JG. Cerebellum and the adaptive coordination of movement. Ann Rev Neurosci 1992; 15: 403442.

21. Goodkin HP, Thach WT. Mechanism of recovery from cerebellar incoordination. Soc Neurosci Abstr 1990; 16: 1317.

22. Asanuma C, Thach WT, Jones EG. Anatomical evidence for segregated focal groupings of efferent cells and their terminal ramifications in the cerebellothalamic pathway of the monkey. Brain Res Rev 1983; 5: 267-297.

23. Asanuma C, Thach WT, Jones EG. Distribution of cerebellar terminations and their relation to other afferent terminations in the ventral lateral thalamic region of the monkey. Brain Res Rev 1983; 5: 237-265.

24. Thach WT, Perry JG, Schieber MH. Cerebellar output: body maps and muscles spindles. In: Palay SL, Chan-Palay V, eds. The Cerebellum - New Vistas. New York: Springer-Verlag 1982; 440-454.

25. Amarenco P, Hauw JJ. Anatomie des arteres cerebelleuses. Rev Neurol (Paris) 1989; 145: 267-276.

26. Amarenco, P, Hauw, JJ. Cerebellar infarction in the territory of the superior cerebellar artery: a clinicopathologic study of 33 cases. Neurology 1990; 40: 1383-1390. 
27. Vilis $T$, Hore J. Effects of changes in mechanical state of limb on cerebellar intention tremor. J Neurophysiol 1977; 40: 1214-1224.

28. Vilis $\mathbf{T}$, Hore $\mathbf{J}$. Central neuronal mechanisms contributing to cerebellar tremor produced by limb perturbations. J Neurophysiol 1980; 43: 279-291.

29. Schieber MH, Thach WT. Trained slow tracking. II. Bidirectional discharge patterns of cerebellar nuclear, motor cortex, and spindle afferent neurons. J Neurophysiol 1985; 55: 1228-1270.

30. Meyer-Lohman J, Hore J, Brooks VB. Cerebellar participation in generation of prompt arm movements. J Neurophysiol 1977; 40: 1038-1050.

31. Spidalieri HJ, Busby L, Lamarre Y. Fast ballistic arm movements triggered by visual, auditory, and somesthetic stimuli in the monkey. II. Effects of unilateral dentate lesion on discharge of precentral cortical neurons and reaction. J Neurophysiol 1983; 50: 1359-1379.

32. Mink JW, Thach WT. Basal ganglia motor control. 2) Late pallidal timing relative to movement onset and inconsistent pallidal coding of movement parameters. J Neurophysiol 1991; 65: 301-329.

33. Mink JW, Thach WT. Basal ganglia motor control. 3) Pallidal ablation: normal reaction time, muscle cocontraction, and slow movement. J Neurophysiol 1991; 65: 330-351.

34. Hore J, Wild B, Diener H-C. Cerebellar dysmetria at elbow, wrist, and fingers. J Neurophysiol 1991; 65: 563-571.

35. Strick PL. The influence of motor preparation on the response of cerebellar neurons to limb displacements. J Neurosci 1983; 3 : 2007-2020.

36. Smith AM, Bourbonnais D. Neuronal activity in cerebellar cortex related to control of prehensile force. J Neurophysiol 1981; 45: 286-303.

37. Frysinger RC, Bourbonnais D, Kalaska JF, Smith AM. Cerebellar cortical activity during antagonist cocontraction and reciprocal inhibition of forearm muscles. J Neurophysiol 1984; 51: 32-49.

38. Wetts R, Kalaska JF, Smith AM. Cerebellar nuclear cell activity during antagonist cocontraction and reciprocal inhibition of forearm muscles. J Neurophysiol 1985; 54: 231-244.

39. Chapman EC, Spidalieri G, Lamarre Y. Activity of dentate neurons during arm movements triggered by visual, auditory, and somesthetic stimuli in the monkey. J Neurophysiol 1986; 55: 203-225.

40. Mackay WA. Cerebellar nuclear activity in relation to simple movements. Exp Brain Res 1988; 71: 47-58.

41. Schieber MH, Thach WT. Trained slow tracking. I. Muscular production of wrist movement. J Neurophysiol 1985; 55: 12131227.

42. Miller RG, Freund HJ. Cerebellar dyssynergia in humans-a quanlitative analysis. Ann Neurol 1980; 8: 574-579.

43. Sanes JN, Lewitt, PA, Mauritz, K-A. Visual and mechanical control of postural and kinetic tremor in cerebellar system disorders. $\mathbf{J}$ Neurol Neurosurg Psychiatry 1988; 51: 934-943.

44. Gauthier GM, Vercher J-L, Mussa Ivaldi F, Marchetti E. Oculomanual tracking of visual targets: control learning, coordination control and coordination model. Exp Brain Res 1988; 73: 127 137.

45. Gauthier GM, Mussa lvaldi F. Oculo-manual tracking of visual targets in monkey: role of the arm afferent information in the control of arm and eye movements. Exp Brain Res 1988; 73: 138154.

46. Vercher J-L, Gauthier GM. Cerebellar involvement in the coordination control of the oculo-manual tracking system: effects of cerebellar dentate nucleus lesion. Exp Brain Res 1988; 73: 155-166.

47. Nieuwenhuys R, Voogd J, van Huijzen Chr. The Human Central Nervous System. Berlin: Springer-Verlag. 3rd Edition 1988.

48. Woodworth RS. The accuracy of voluntary movement. Psychological monographs 1899; 3: 1-114.

49. Morasso P. Spatial control of arm movements. Exp Brain Res 1981; 42: 223-227.

50. Abend W, Bizzi E, Morasso P. Human arm trajectory formation. Brain 1982; 105: 331-349.

51. Soechting JF, Laquaniti F. Invariant characteristics of a pointing movement in man. J Neurosci 1981; 1: 710-720.
52. Hollerbach JM, Atkeson CG. Characterization of joint-interpolated arm movements. Exp Brain Res Suppl 1986; 15: 41-54.

53. Gilman S, Carr D, Hollenberg J. Kinematic effects of deafferentation and cerebellar ablation. Brain 1976; 99: 311-330.

54. Botterell EH, Fulton JF. Functional localization in the cerebellum of primates. Il. Lesions of midline structures (vermis) and deep nuclei. J Comp Neurol 1938; 69: 47-62.

55. Sprague JM, Chambers WW. Regulation of posture in intact and decerebrate cat. I Cerebellum, reticular formation, and vestibular nuclei. J Neurophysiol 1953; 16: 451-463.

56. Botterell EH, Fulton JF. Functional localization in the cerebellum of primates. III. Lesions of hemispheres (neocerebellum). J Comp Neurol 1938; 69: 63-87.

57. Chambers, WW Sprague, JM. Functional localization in the cerebellum. I. Organization in longitudinal corticonuclear zones and their contribution to the control of posture, both extrapyramidal and pyramidal. J Comp Neurol 1955; 103: 105-129.

58. Chambers WW, Sprague JM. Functional localization in the cerebellum. II. Somatic organization in cortex and nuclei. Arch Neurol Psychiatry 1955; 74: 653-680.

59. Beaubaton D, Trouche, E. Participation of the cerebellar dentate nucleus in the control of a goal-directed movement in monkeys. Effects of reversible or permanent dentate lesion on the duration and accuracy of a pointing response. Exp Brain Res 1982; 46: 127-138.

60. Rispal-Padel L, Circirata F, Pons C. Cerebellar nuclear topography of simple and synergistic movements in the alert baboon. Exp Brain Res 1982; 47: 365-380.

61. Rispal-Padel L, Cicirata F, Pons J-C. Neocerebellar synergies. Exp Brain Res Suppl 1983; 7: 213-223.

62. MacKay WA. Unit activity in the cerebellar nuclei related to arm reaching movements. Brain Res 1988; 442: 240-254.

63. Asanuma, C, Thach, WT, Jones, EG. Brainstem and spinal projections of the deep cerebellar nuclei in the monkey, with observations on the brainstem projections of the dorsal column nuclei. Brain Res Rev 1983; 5: 299-322.

64. Schell GR, Strick PL. The origin of thalamic inputs to the arcuate premotor and supplementary motor areas. J Neurosci 1983; 4: 539-560.

65. Orioli PJ, Strick PL. Cerebellar connections with the motor cortex and the arcuate premotor area: an analysis employing retrograde transneuronal transport of WGA-HRP. J Comp Neurol 1989; 288: 612-626.

66. Asanuma H. The pyramidal tract. In: Brooks VB, ed. Handbook of Physiology, The Nervous System, Section 1 1981; 2: 702-733.

67. Cheney PD, Fetz, EE. Functional classes of primate corticomotoneuronal cells and their relation to active force. J Neurophysiol 1980; 44: 773-791.

68. Fetz EE, Cheney PD. Postspike facilitation of forelimb muscle activity by primate corticomotoneuronal cells. J Neurophysiol 1980; 44: 751-772.

69. Muir RB, Lemon RN. Corticospinal neurons with a special role in precision grip. Brain Res 1983; 261: 312-316.

70. Schieber MH. Motor fields of motor and premotor cortex neurons in the rhesus monkey during independent finger movements. Soc Neurosci Abstr 1988; 14: 821.

71. Ghez C, Vicario, D. Discharge of red nucleus during isometric muscle contraction: activity patterns and correlations with isometric force. J Physiol (Paris) 1978; 74: 283-285.

72. Kohlerman NJ, Gibson AR, Houk JC. Velocity signals related to hand movements recorded from red nucleus neurons in monkeys. Science 1982; 217: 857-860.

73. Lawrence DG, Kuypers HGJM. The functional organization of the motor system in the monkey. I. The effects of bilateral pyramidal lesions. Brain 1968; 91: 1-14.

74. Lawrence DG, Kuypers HGJM. The functional organization of the motor system in the monkey. II. The effects of lesions of the descending brainstem pathways. Brain 1968; 91: 15-36.

75. Schieber MH, Kim L, Thach WT. Muscimol in monkey area 4 impairs individuated finger movements, in area 6 produces contralateral neglect. Soc Neurosci Abstr 1991; 17: 1021. 
76. Mugnaini $E$. The length of cerebellar parallel fibers in chicken and rhesus monkey. J Comp Neurol 1983; 220: 7-15.

77. Rondot P, Bathien N, Toma S. Physiopathology of cerebellar movement. In: Massion J, Sasaki K, eds. Cerebro-cerebellar Interactions. Amsterdam: Elsevier 1979; 203-230.

78. Alstermark B, Lindstrom S, Lundberg A, Sybirska E. Integration in descending motor pathways controlling the forelimb in the cat.
Ascending projection to the lateral reticular nucleus from $\mathrm{C} 3$ $\mathrm{C} 4$ - propriospinal neurons also projecting to forelimb motor neurons. Exp Brain Res 1981; 42: 282-298.

79. MacKay WA, Murphy JT. Cerebellar modulation of reflex gain. Prog Neurobiol 1979; 13: 361-417. 